DOCUMENTS

pour l'histoire

des techniques
Documents pour l'histoire des techniques

Nouvelle série

$14 \mid 2^{\mathrm{e}}$ semestre 2007

Actes de la journée d'études doctorales en histoire des techniques (8 mars 2004)

\title{
Zhang Liang, La Naissance du concept de patrimoine en Chine, XIXe-XXe siècles
}

Paris, Archithèses, Éditions Recherches/Ipraus, 2004, 288 pages, illustr., bibliographie.

\section{André Guillerme}

\section{(2) OpenEdition}

Édition électronique

URL : http://journals.openedition.org/dht/1128

DOI : $10.4000 /$ dht. 1128

ISSN : 1775-4194

Éditeur :

Centre d'histoire des techniques et de l'environnement du Cnam (CDHTE-Cnam), Société des élèves du CDHTE-Cnam

\section{Édition imprimée}

Date de publication : 1 décembre 2007

Pagination : 153-154

ISBN : 978-2-9530779-0-2

ISSN : 0417-8726

Référence électronique

André Guillerme, «Zhang Liang, La Naissance du concept de patrimoine en Chine, XIXe-XXe siècles », Documents pour l'histoire des techniques [En ligne], 14 I $2^{\mathrm{e}}$ semestre 2007, mis en ligne le 03 novembre 2010, consulté le 21 septembre 2020. URL : http://journals.openedition.org/dht/1128 ; DOI : https:// doi.org/10.4000/dht. 1128

Ce document a été généré automatiquement le 21 septembre 2020.

(c) Tous droits réservés 


\section{Zhang Liang, La Naissance du concept de patrimoine en Chine, XIXe-XXe siècles}

Paris, Archithèses, Éditions Recherches/Ipraus, 2004, 288 pages, illustr., bibliographie.

André Guillerme

\section{RÉFÉRENCE}

Zhang Liang, La Naissance du concept de patrimoine en Chine, XIXe-XXe siècles, Paris, Archithèses, Éditions Recherches/Ipraus, 2004, 288 pages, illustr., bibliographie.

1 Cet ouvrage relatif au patrimoine chinois est doublement d'actualité. D'abord, il analyse l'émergence, récente, en Chine, de ce concept forgé au XIXe siècle en Europe de l'Ouest, ensuite il invite à analyser la folle urbanisation qui, sous nos yeux, démantèle irréversiblement la ville chinoise ancienne. À l'origine, le travail de Zhang Liang est un mémoire de thèse d'architecture - urbanisme et aménagement - fouillé, érudit, pertinent. Comme toute thèse même vulgarisée, on y trouve quelques lourdeurs et faux-sens, mais pardonnables face à l'intérêt qu'elle suscite. La bibliographie est copieuse et paraît exhaustive quant à la documentation chinoise.

2 L'auteur fait d'abord l'inventaire de ce que nous appelons "patrimoine ", qu'on distingue en France de l'« héritage »: dans le patrimoine, on sent de l'historicité, de l'identité, de l'authenticité; dans l'héritage il n'y a pas forcément du goût, mais une charge à assumer; dans le patrimoine, il y a de la valeur, du beau, du transmissible. Du moins pour ce qui concerne le patrimoine public occidental, d'abord français et révolutionnaire - l'abbé Grégoire contre le vandalisme des Sans-culottes est le père fondateur - puis romantique - Prosper Mérimée est le premier inspecteur - et architectural, puis urbain ; ce patrimoine est aujourd'hui universel - l'eau, les sites - et 
humanitaire - classé par l'Unesco (voir F. Choay, L'Allégorie du patrimoine, Paris, Le Seuil, 1995).

3 En Chine, l'authenticité fait place à l'éternité : le monument n'est pas nécessaire du moment qu'un lettré l'a mis en écriture, l'a encré dans un rouleau et l'a fait savoir. La temporalité fait place au souvenir, à la trace calligraphique : le monument se perpétue dans la poétique de l'espace.

4 «Monument »-en chinois jinian pei, stèle commémorative - est plutôt récent et s'est imposé par le biais d'une pratique «translinguistique ». Pourtant, les racines du mot, $j i$ et nian, désignent l'une et l'autre « les années passées ou les temps anciens, la mémoire ou le souvenir » (p. 51). Concept nomade, le patrimoine s'appelle guwu à Taiwan et wenwu en Chine continentale, étymologiquement «ensemble des rites et des institutions sacrés ».

5 En Chine, la modernité intervient au début du XXe siècle dans un empire déjà fatigué. En 1914, le ministre de l'Intérieur et préfet de Pékin, Zhu, y crée le nouveau parc public en lieu de l'Autel du dieu du Sol et des Céréales, avec le soutien de la bourgeoisie : des portes urbaines sont refaites pour s'adapter aux transports ferroviaires et décongestionner les abords. Les représentations du prince, signes de la Chine immuable, sont malmenées, provoquant ainsi « l'éveil de la conscience» (p. 59).

6 Le patrimoine historique bâti se reconnaît en Chine avec la montée de la conscience nationale (comme en Europe au milieu du XIXe siècle) au tout début du XXe siècle. Il évolue en même temps que le développement des musées nationaux (1912, création) et des institutions chargées du patrimoine (1928, protection des objets anciens, devenu "Comité de gestion», puis «Bureau (1950) des reliques culturelles» dans le gouvernement communiste). La reconnaissance du patrimoine chinois est due en grande partie à la "Société d'études sur les constructions chinoises » fondée par Zhu Giqian en 1930. Dès 1925, cet architecte, éduqué à l'américaine, écrit le premier traité de construction chinoise et sa Société en publiera une trentaine entre 1932 et 1935 . Elle édite aussi un extraordinaire vocabulaire de la construction chinoise, pour s'imposer face au dictionnaire de construction japonaise (publié en 1927) alors que sévit l'invasion nippone et l'occupation de la Mandchourie. La Société fondée en 1930 « invente ", au sens archéologique, près de trois mille monuments anciens entre 1930 et 1937 : elle fait de l'architecture, jusque-là considérée comme une forme inférieure de la culture, un support de valeurs, un patrimoine.

7 Autre " héraut » du patrimoine, Liang Sicheng, architecte lui aussi, qui repère et classe l'architecture monumentale, qui en fait une grammaire (p. 83). Il adopte le principe «restaurer l'ancien comme à l'état d'ancien ». Il reprend les recherches de l'Américain Murphy, chargé d'édifier une université, fille de Yale, à Changshi, relatives à l'architecture palatine - toiture incurvée, construction claire, proportion, authenticité. Liang Sicheng, Viollet le Duc national, définit le nouveau style chinois à travers ses nombreux projets à Nankin, alors capitale : le plus connu est le mausolée Sun Yatsen, en partie construit en béton armé, matériau de la modernité (p. 107).

8 À l'avènement du gouvernement communiste, deux courants de pensée patrimoniale s'affrontent, l'un culturaliste, mené à l'instigation de Liang Sicheng défend la continuité culturelle en milieu urbain et étend le patrimoine sur le site, voir la ville: Pékin doit en être l'archétype. L'autre, progressiste, prosoviétique, ne veut conserver de monuments historiques que ceux qui témoignent de la lutte des classes. Pékin doit en être le modèle. Ce n'est point «une pensée stalinienne»-A. Kopp avait déjà 
souligné l'émergence de cette idéologie dans les années 20, dans Ville et Révolution (Paris, Le Seuil, 1970)-, mais une pensée positiviste qui tient à effacer - non à vandaliser - les traces du joug aristocratique pour ordonner un nouveau paysage, de nouveaux alignements, pour « changer la ville consommatrice en ville productive » ( $\mathrm{p}$. 115). Ici, l'industrie est patrimoine, l'usine le témoin de l'action culturelle; la ville, force ouvrière. D'où un nouvel urbanisme qui fait du centre un lieu de manifestation du gouvernement du peuple - la place Tien'an Men et l'avenue Chang'an. Urbanisme destructeur des années 50 qui impose un schéma fonctionnaliste, façon charte d'Athènes, qui quadrille la cité d'infrastructures larges et rectilinéaires. (n. 33 p. 127), démantèle les remparts millénaires, détruit le patrimoine historique. Entre 1966 et 1976, la révolution culturelle fait le reste.

9 Contre cela, Zhang Liang s'est fait avocat de la cause culturaliste, dénonce la brutalité contemporaine et met en avant un urbanisme protecteur. S'inspirant des théories urbanistiques anglo-saxonnes il propose de faire des îlots insalubres des espaces verts. Il veut libérer la cité, réduire la densité et la concentration.

Une certaine renaissance patrimoniale apparaît dans le statut de «ville célèbre d'histoire et de culture" instaurée en 1982 sous la pression des lettrés et des architectes. La loi de protection du patrimoine du 19 novembre 1982 désigne ainsi « les villes pourvues d'un patrimoine particulièrement riche... d'une valeur historique et d'une signification révolutionnaire très importantes ", les villes dotées d'un fengmao, d'une "physionomie stylistique » (p. 157). «Cela peut avoir une grande répercussion sur l'édification de la civilisation spirituelle du socialisme et le développement de l'entreprise touristique de notre pays ", dicte la loi. 24 villes classées en 1982, 36 autres en 1986, 37 en 1993, soit une centaine pour un total de 3000, ce qui est peu - $3 \%$. Le classement est défini par le Bureau de gestion des reliques culturelles; il fonctionne comme pour les monuments historiques en donnant priorité aux sites historiques, aux lieux célèbres de paysage -iconographie spécifique à l'Extrême-Orient, voir les meisho japonais - et aux sites révolutionnaires de la culture des minorités nationales. En 1993, la législation évolue et admet une nouvelle spécificité, la « zone de protection d'histoire et de culture ». Rien en revanche sur ce qui a fait la puissance économique de la Chine : le patrimoine industriel. Point de sauvegarde de manufactures d'armement, de filatures, de temples sidérurgiques, de centrales, de sites miniers, comme ce fut le cas en Union soviétique ou en Allemagne de l'Est où l'on sauvegardait pour mémoire les traces de la force -et de la sueur- des travailleurs, force socialiste. Pourquoi donc?

\section{AUTEURS}

ANDRÉ GUILLERME

CDHTE-Cnam 